\title{
EFFECT OF A SYNTHESIS FORMULATION ON THE THERMAL PROPERTIES OF POLYURETHANE
}

\author{
VPLIV OBLIKOVANJA SINTEZE NA TERMIČNE LASTNOSTI \\ POLIURETANA
}

\author{
Ruien Yu ${ }^{1,2,3 *}$, Yanfei Kou ${ }^{1,3}$, Lina Cai ${ }^{2}$, Changxin Fan², Yanjun Shao ${ }^{3}$, Xiaoyan \\ Zhang $^{2}$, Xijing Zhu ${ }^{1,3}$ \\ ${ }^{1}$ School of Mechanical Engineering, North University of China, No. 3 Xueyuan Road, Taiyuan 030051 Shanxi, P. R. China \\ ${ }^{2}$ Shanxi Transportation Technology Research \& Development Co., Ltd, No. 27 Wuluo Road, Taiyuan 030032 Shanxi, P. R. China \\ ${ }^{3}$ Shanxi Key Laboratory of Advanced Manufacturing Technology, North University of China, Taiyuan 030051 Shanxi, P. R. China
}

Prejem rokopisa - received: 2019-04-30; sprejem za objavo - accepted for publication: 2019-12-23

doi:10.17222/mit. 2019.092

\begin{abstract}
In this paper, the effect of a synthesis formulation on the thermal properties of polyurethane was studied. Based on the design of the polyurethane hard-segment content and isocyanate index, 10 kinds of TPU were synthesized with the prepolymer method. The molecular weight of TPU was determined with GPC, the thermal behavior of TPU was studied with differential scanning calorimetry (DSC) and a thermal gravimetric analysis (TGA), and the molecular structure was studied with Fourier-transform infrared spectroscopy (FTIR). The results showed that TPUs with different synthetic formulations exhibited different heat absorptions during differential scanning calorimetry, and the heat resistance of the TPU with $20 \%$ hard segment was better than the TPU with $40 \%$ hard segment.

Keywords: polyurethanes, synthesis, thermal properties, structure

V pričujočem članku avtorji opisujejo študijo vpliva oblikovanja sinteze na termične lastnosti poliuretana. Na temelju izbire vsebnosti trdega segmenta v poliuretanu in izocianatnega indeksa, so avtorji s prepolimerno metodo sintetizirali 10 različnih vrst termoplastičnega poliuretana (TPU). Molekularno maso TPU so določili z gelsko izključitveno kromatografijo (GPC, angl.: Gel Permeation Chromatography), termične lastnosti TPU so študirali z diferencialno vrstično kalorimetrijo (DSC, angl.: Differential Scanning Calorimetry) in termogravimetrično analizo (TGA). Molekularno strukturo TPU pa so študirali s Fourierjevo transformacijsko infrardečo spektroskopijo (FTIR). Rezultati študije so pokazali, da TPU, sintetiziran na različne načine, kaže različno absorpcijo toplote in da je termična stabilnost TPU z večjim deležem trdega segmenta (40 \%), večja kot tista z manjšim deležem trdega segmenta $(20 \%)$.

Ključne besede: poliuretani, sinteza, termične lastnosti, struktura
\end{abstract}

\section{INTRODUCTION}

Polyurethane is a polymer compound which has a repeating carbamate group (-NHCOO-) on its molecular backbone. ${ }^{1,2}$ Different synthesis substances and different chain-extension reactions generate a wide range of polyurethane. ${ }^{3}$ So, it can be used to produce plastic, ${ }^{4}$ hard and soft foam, ${ }^{5}$ elastomers, ${ }^{6}$ fibers, ${ }^{7}$ adhesives, ${ }^{8}$ biomedical materials ${ }^{9}$ and coatings. ${ }^{10}$ In the field of packaging, polyurethane is mainly used for two or more layers of plastic film between the bonding, especially dry composite film, mainly for drugs, ${ }^{11}$ food ${ }^{12}$ and other goods. ${ }^{13}$ In addition, it can also be used for paper and plastic composites, ${ }^{14}$ mainly stickers advertising paper or carton packaging.

In recent years, more and more scholars have devoted themselves to the modification of polyurethane and development of a waterborne polyurethane. S. K. Dogan et al. ${ }^{15}$ studied and obtained PLA/TPU composites with a thermal response and shape-recovery properties. P. Alagi et al. ${ }^{16}$ transformed castor oil and soybean oil into

*Corresponding author's e-mail:

yuruien@nuc.edu.cn (Ruien Yu) polyols to prepare TPU and obtain a modified TPU with excellent toughness and transparency. W. Q. Lei et al. ${ }^{17}$ found three kinds of representative chain extenders to prepare polyurethane elastomers. The effects of chain extenders on the morphology and thermal properties of polyurethane were studied. Y. Xiao et al. ${ }^{18}$ investigated the effect of a microphase separation on the crystallization of the soft segment of green waterborne polyurethane. It was found that the phase separation hindered the crystallization of the soft-segment phase and that the high phase separation lowered the crystallization capacity, crystallinity and the amount of crystals of the soft segment.

Polyurethane prepolymer is produced by reacting isocyanate and polyether polyol in the initial phase, and finally converted to a polymer with polymer chains using the chain extension and curing processes; thus, the chemical structure and properties of polyurethane are changed. Our group was engaged in the research of polyurethane-modified asphalt. ${ }^{19,20}$ Thermoplastic polyurethane was synthesized with the prepolymer method to modify the asphalt. The small-molecule polyurethane prepolymer produced during the initial stage of the 
Table 1: Raw materials of TPU and their molecular structures

\begin{tabular}{|l|l|l|}
\hline \multicolumn{1}{|c|}{ Chemical name } & Abbreviation \\
\hline 4,4'-diphenylmethane diisocyanate & Structure \\
\hline Polytetramethylene ether glycol &
\end{tabular}

reaction between isocyanate and polyester polyol can form a uniform system and has good compatibility with asphalt. ${ }^{21}$ However, with the process of chain extension and curing, polyurethane prepolymers gradually produce polymers with high molecular chains through chemical reactions. ${ }^{22}$ The changed chemical structure and thermal properties have different modification effects on the base asphalt. In this study, the effect of the polyurethanesynthesis formulation on the thermal properties was studied by controlling the synthesis process.

\section{EXPERIMENTAL PART}

\subsection{Materials}

4,4'-diphenylmethane diisocyanate (a molecular weight of 250), polytetramethylene ether glycol a molecular weight of 2000), 1,4-butanediol (a molecular weight of 90) were provided by Shanghai Aladdin Biochemical Science \& Technology Co., Ltd. The structure of the three raw materials is shown in Table $\mathbf{1}$.

\subsection{Experiment design and calculation}

The hard-segment content in the polyurethane chemistry is the mass fraction of the hard segment in the TPU, and the mass of the hard segment is the sum of diisocyanate and small molecular diol. The isocyanate index is the ratio of the equivalent number of diisocyanate to the sum of the equivalent number of oligomeric polyol and small molecule diol, namely the $\mathrm{NCO} / \mathrm{OH}$ ratio. The three raw materials are bifunctional groups and the $\mathrm{NCO} / \mathrm{OH}$ is also the molar ratio.

$$
\begin{gathered}
C_{h}=\frac{W_{i}+W_{d}}{W_{i}+W_{d}+W_{g}} \\
r=\frac{n_{\mathrm{NCO}}}{n_{\mathrm{OH}}}=\frac{\frac{W_{i}}{\bar{M}_{i}}}{\frac{W_{d}}{\bar{M}_{d}}+\frac{W_{g}}{\bar{M}_{g}}}
\end{gathered}
$$

Based on Equations (1) and (2), the following is obtained:

$$
C_{h}=\frac{r \cdot \frac{W_{g}}{\bar{M}_{g}} \cdot \bar{M}_{i}+\left(1+\frac{r \cdot \bar{M}_{i}}{\bar{M}_{d}}\right) \cdot W_{d}}{\left(\frac{r \cdot \bar{M}_{i}}{\bar{M}_{d}}+1\right) \cdot W_{d}+\left(\frac{r \cdot \bar{M}_{i}}{\bar{M}_{g}}+1\right) \cdot W_{g}}
$$

In Equations (1-3), $W_{i}, W_{d}$, and $W_{g}$ are the weights of MDI, BDO and PTMEG, respectively; $M_{i}, M_{d}$ and $M_{g}$ are the molecular weights of MDI, BDO and PTMEG, respectively; $C_{h}$ is the hard-segment content of polyurethane; $r$ is the isocyanate index.

In this study, the hard-segment content is $20 \%$ and $40 \%$ while isocyanate index $\mathrm{NCO} / \mathrm{OH}$ is controlled at $0.95,0.98,1,1.02$ and 1.05. The mass values of BDO and MDI are calculated on the basis of 100-g PTMEG. The formulation of the 10 kinds of TPU to be synthesized is shown in Table 2.

Table 2: Synthesis formulation of TPU

\begin{tabular}{|c|c|c|c|c|c|}
\hline No. & $C_{h}$ & $r$ & $W_{g} / g$ & $W_{i} / g$ & $W_{d} / g$ \\
\hline $1^{\#}$ & $20 \%$ & 0.95 & 100 & 21.39 & 3.607 \\
\hline $2^{\#}$ & $20 \%$ & 0.98 & 100 & 21.58 & 3.426 \\
\hline $3^{\#}$ & $20 \%$ & 1 & 100 & 21.69 & 3.309 \\
\hline $4^{\#}$ & $20 \%$ & 1.02 & 100 & 21.8 & 3.195 \\
\hline $5^{\#}$ & $20 \%$ & 1.05 & 100 & 21.97 & 3.032 \\
\hline $6^{\#}$ & $40 \%$ & 0.95 & 100 & 51.606 & 15.056 \\
\hline $7^{\#}$ & $40 \%$ & 0.98 & 100 & 52.05 & 14.62 \\
\hline $8^{\#}$ & $40 \%$ & 1 & 100 & 52.325 & 14.337 \\
\hline $9^{\#}$ & $40 \%$ & 1.02 & 100 & 52.598 & 14.064 \\
\hline $10^{\#}$ & $40 \%$ & 1.05 & 100 & 52.991 & 13.669 \\
\hline
\end{tabular}

\subsection{Preparation of polyurethane}

TPU was synthesized with the prepolymer method. The detailed operation is as follows: we put the weighed PTMEG in a 500-mL, dry, three-necked flask, in a $110{ }^{\circ} \mathrm{C}$ oil bath (model DF-101S, Shaanxi Taikang Biotechnology Co., Ltd.), heated it with a $20 \mathrm{~mL} / \mathrm{min}$ flow of dry nitrogen for protection, stirred it (R30, Shanghai Fluko Technology Development Co., Ltd.) at a speed of $200 \mathrm{~min}^{-1}$ and dehydrated it for $90 \mathrm{~min}$. The temperature of the system was then reduced to $80{ }^{\circ} \mathrm{C}$. The MDI, which had been weighed and dried in an oven at $80{ }^{\circ} \mathrm{C}$, was added to the system and kept at constant temperature and speed for $2 \mathrm{~h}$. When the viscosity of the system increased, producing blue light, the polyurethane pre- 
polymer was prepared successfully. The temperature of the system was then reduced to $50{ }^{\circ} \mathrm{C}$; the $\mathrm{BDO}$ was weighed; the stirrer's speed was increased to $400 \mathrm{~min}^{-1}$; the stirring continued for $10 \mathrm{~min}$; the temperature of the system was raised to $100{ }^{\circ} \mathrm{C}$; the synthesized polymer was poured into the container coated with Teflon; and, finally, the required TPU samples were successfully synthesized after the curing at $100{ }^{\circ} \mathrm{C}$. In the case of high hardness and a high isocyanate index, the viscosity of the system was increased rapidly after adding BDO. In order to facilitate the discharge, the mixture was quickly mixed and the stirring time was appropriately adjusted according to the viscosity.

\subsection{Characterization}

The molecular weight and molecular-weight distribution of TPU were measured with Waters 515-2414 gel permeation chromatography (Waters, USA), with tetrahydrofuran as the mobile phase, a flow rate of $1 \mathrm{~mL} / \mathrm{min}$, a column temperature of $35{ }^{\circ} \mathrm{C}$ and a detector temperature of $35{ }^{\circ} \mathrm{C}$. The samples were dissolved with chromatographic tetrahydrofuran.

The endothermic, exothermic and crystalline behavior of the TPU was tested using a DSC 200F3 differential scanning calorimeter (NETZSCH, Germany). The nitrogen protection was carried out at a flow of $60 \mathrm{~mL} / \mathrm{min}$, with the purge gas also being nitrogen, at a flow of $30 \mathrm{~mL} / \mathrm{min}$, in a temperature range between $-100{ }^{\circ} \mathrm{C}$ and $-300{ }^{\circ} \mathrm{C}$ and a heating rate of $10 \mathrm{k} / \mathrm{min}$. A $40-\mu \mathrm{L}$ standard alumina crucible was used and the sample amount was 5-10 mg.

The loss of the TPU in the above temperature range was tested using a TG 209F3 thermogravimetric analyzer (NETZSCH, Germany). The nitrogen protection was carried out at a flow of $20 \mathrm{~mL} / \mathrm{min}$, while nitrogen purging took place at a flow of $30 \mathrm{~mL} / \mathrm{min}$ in a temperature range of $100-800{ }^{\circ} \mathrm{C}$ and at a heating rate of $10 \mathrm{k} / \mathrm{min}$. The sample amount in the alumina crucible was $10-15 \mathrm{mg}$.

The molecular structure of the TPU was determined with FTIR-8400S Fourier transform infrared spectroscopy (Shimadzu, Japan) with a scanning range of $400-4000 \mathrm{~cm}^{-1}$, a scanning frequency of 25 and a resolution of $16.0 \mathrm{~cm}^{-1}$.

\section{RESULTS AND DISCUSSION}

\subsection{Molecular weight}

TPU is a linear molecule; its molecular weight is the key indicator of its properties. In the synthesis of TPU, the $\mathrm{NCO} / \mathrm{OH}$ ratio (the $r$ value) plays an important role in controlling the molecular weight. When $r \leq 1.0$, the molecular weight of TPU increases with the increase in the $r$ value. When $r=1$, the TPU molecular weight reaches the highest value. When $r \geq 1$, and the $r$ value continues to increase, the TPU molecular weight declines. Table 3 shows the molecular weight and polydispersity index of the TPU. The molecular weight of the TPU does not increase first and then decrease as the $r$ value increases, but the maximum molecular weight of TPU is at $r=1.05$. The purity of raw materials, calculation and measurement error, mixing, environmental humidity and many other factors very easily make the actual $r$ value deviate from the designed value; so they are the reasons for the deviation of the actual molecular weight and theoretical molecular weight. ${ }^{23}$ The content of hard segment increased, the content of the -NCO group increased while the TPU molecular weight decreased. In addition, -NCO continued to react with moisture, urea and carbamate to form urea, biuret and allophanate, respectively. TPU branched or crosslinked and could not be dissolved in THF, so we failed to measure the molecular weight of TPU samples 6\#, 8\# and 10\#. The occurrence of side reactions in the process of polymer synthesis was also a cause for the molecular-weight dispersion of the polymer. The larger the PDI, the wider was the molecular-weight distribution.

Table 3: Molecular weight and the polydispersity index of TPU samples

\begin{tabular}{|c|c|c|c|c|c|}
\hline TPU & $C_{h}$ & $r$ & $\#$ & $\#$ & $\#$ \\
\hline $1^{\#}$ & $20 \%$ & 0.95 & 70,386 & 147,839 & 2.1 \\
\hline $2^{\#}$ & $20 \%$ & 0.98 & 58,104 & 110,647 & 1.904 \\
\hline $3^{\#}$ & $20 \%$ & 1 & 75,597 & 220,379 & 2.915 \\
\hline $4^{\#}$ & $20 \%$ & 1.02 & 105,264 & 277,144 & 2.633 \\
\hline $5^{\#}$ & $20 \%$ & 1.05 & 414,826 & $1,046,191$ & 2.522 \\
\hline $\mathrm{r}^{\#}$ & $40 \%$ & 0.95 & - & - & - \\
\hline $7^{\#}$ & $40 \%$ & 0.98 & 51,669 & 281,597 & 5.45 \\
\hline $8^{\#}$ & $40 \%$ & 1 & - & - & - \\
\hline $9^{\#}$ & $40 \%$ & 1.02 & 76,825 & 255,620 & 3.327 \\
\hline $10^{\#}$ & $40 \%$ & 1.05 & - & - & - \\
\hline
\end{tabular}

\subsection{Thermal behavior}

In terms of morphology, TPU molecules have a two-phase structure: the soft segment belongs to the soft-segment phase and the hard segment belongs to the hard-segment phase. ${ }^{24}$ When the hard content is $20 \%$, the soft segment phase appears to be crystalline, while the hard segment is amorphous. In Figure 1a, the glass-transition temperature of the TPU occurs between $-63{ }^{\circ} \mathrm{C}$ and $-60{ }^{\circ} \mathrm{C}$. The endothermic peak appears at $10-20{ }^{\circ} \mathrm{C}$, being the result of the proximity order and the amorphous hard-segment melting; the melting peak gradually decreases and the heat absorption decreases with the increase in the molecular weight of the TPU. In Figure 1b, the hard-segment content increases and crystals appear in it. The endothermic melting peaks at (170, 190 and 220) ${ }^{\circ} \mathrm{C}$ indicate the remote-ordered hard segment and the crystalline-state hard-segment phase, while the heat absorption of the melting peaks increases with the increase in the isocyanate index. The formation of urea and allophanate in the reaction process makes the melting peaks in the hard-segment crystallization zone 


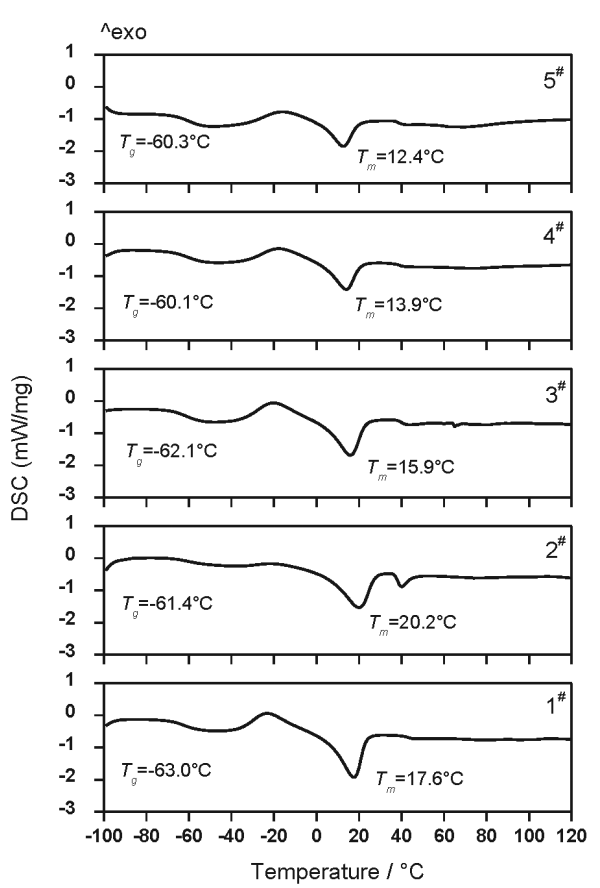

Figure 1: DSC curves of the PU samples

different. Compared with $20 \%$ hard-segment content of TPU samples $1 \#-5 \#$, the content of the proximity-ordered hard segments is reduced and the amount of heat
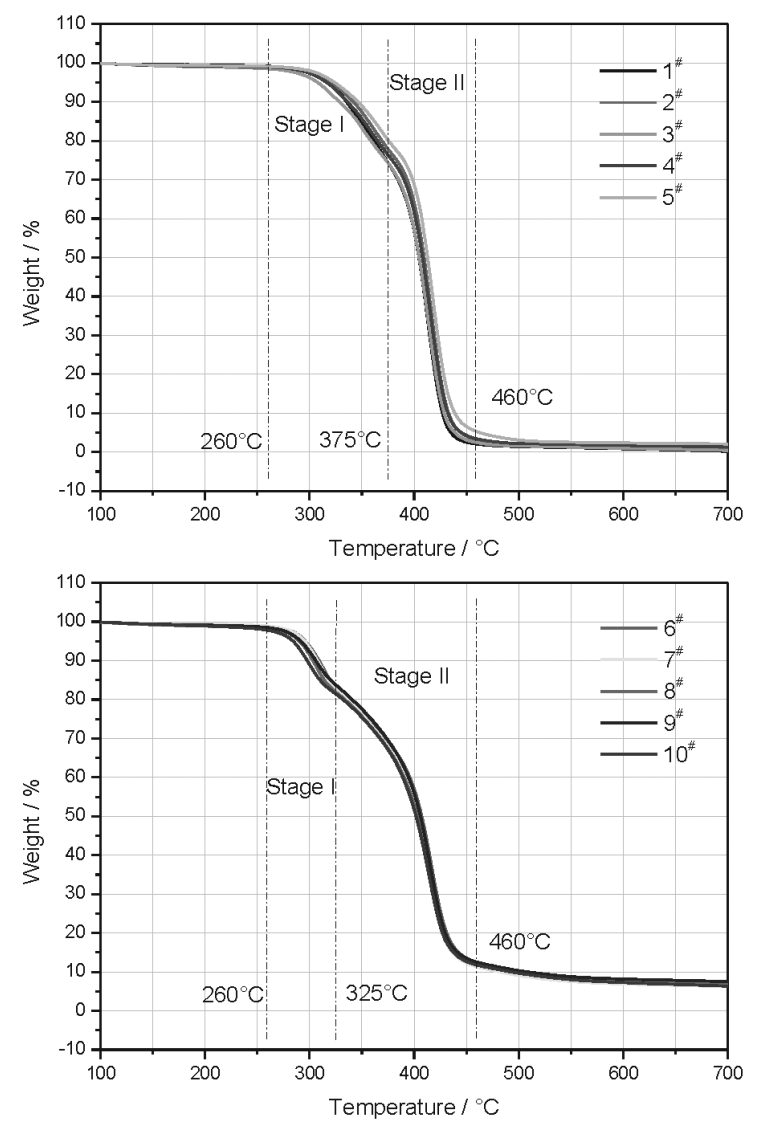

Figure 2: TGA curves of the PU samples

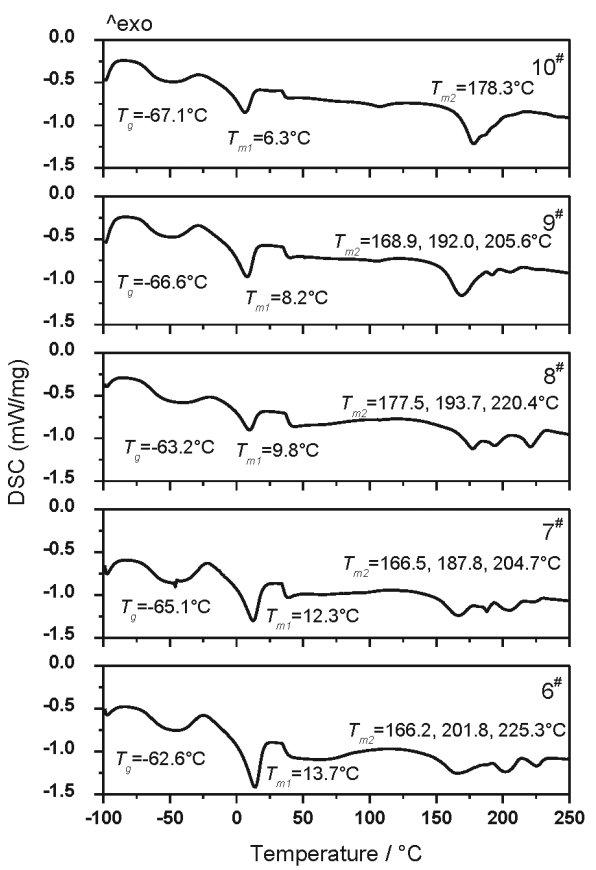

absorption is gradually reduced, while the peak is moved forward. The MDI/BDO aromatic-ring hard segment is crystalline; the high-degree crystallization of the hard segment is conducive to the purification of the soft-segment phase and the glass-transition temperature of the TPU is reduced.

\subsection{Thermal degradation}

The heat resistance of the polymer is measured based on its thermal-decomposition temperature. Figures $\mathbf{2}$ and 3 show the TGA and DTG curves for the TPU, respectively. The TPU samples with two different hard segments are all subjected to two degradation processes. The TPU with $20 \%$ hard segment is in temperature ranges of $260-375{ }^{\circ} \mathrm{C}$ and $375-460{ }^{\circ} \mathrm{C}$, while $40 \%$ hard segment is in temperature ranges of $260-325{ }^{\circ} \mathrm{C}$ and $325-460{ }^{\circ} \mathrm{C}$. The degradation of the first stage is the decomposition of the carbamate in the hard segment. The hard-segment content increases, the hard-segment phase crystallizes, the degradation difference between this stage and the second stage of $40 \%$ hard-segment content of the TPU is more obvious than that of $20 \%$ hardsegment content of the TPU, and the degradation rate reaches the maximum at $307{ }^{\circ} \mathrm{C}$. Urea, biuret and allophanate ar produced during the preparation of the TPU with a different isocyanate index. The decomposition temperature of these groups is different from the decomposition temperature of the carbamate group, causing differences in the degradation temperature and degradation rate. The second stage is the degradation of oligomer diol; the highest degradation rates of the two types of the TPU samples were all in the vicinity of $415{ }^{\circ} \mathrm{C}$. Finally, the degradation included the carbon 


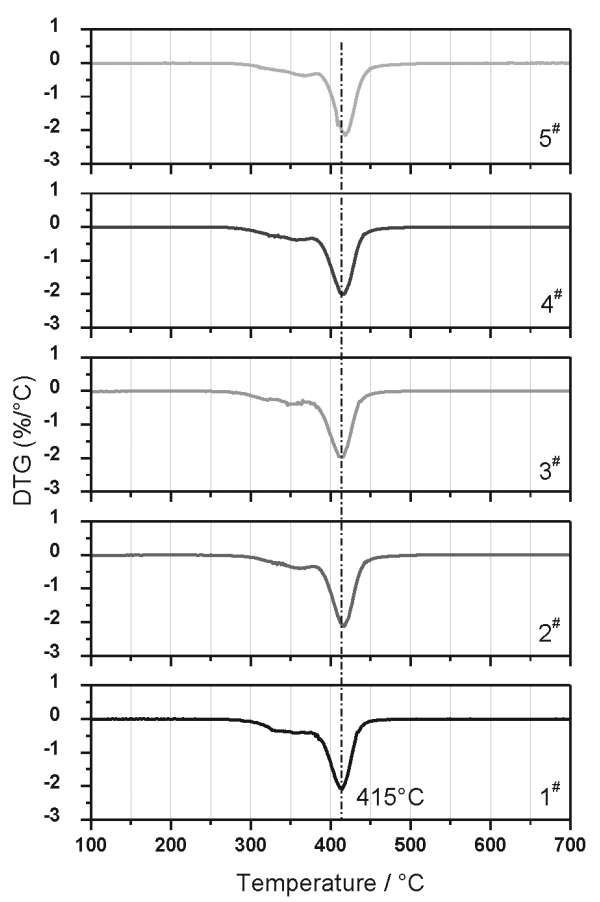

Figure 3: DTG curves of the PU samples

chain and aromatic ring; the benzene-ring content of $40 \%$ hard content of the TPU is large and difficult to degrade and the final residue is greater than that of $20 \%$ hard-segment content of the TPU. Considering (10, 20, 30 and 40) \% TPU degradation, the heat resistance of $20 \%$ hard-segment content of the TPU is better than that of $40 \%$ hard-segment content of the TPU, and it is known from the TGA curve in Figure 3 that TPU sample $5 \#$ is the best.

\subsection{FTIR analysis}

Polyurethane molecules are often the existing structures such as urethane, hydrocarbyl, phenyl, ester, ether,

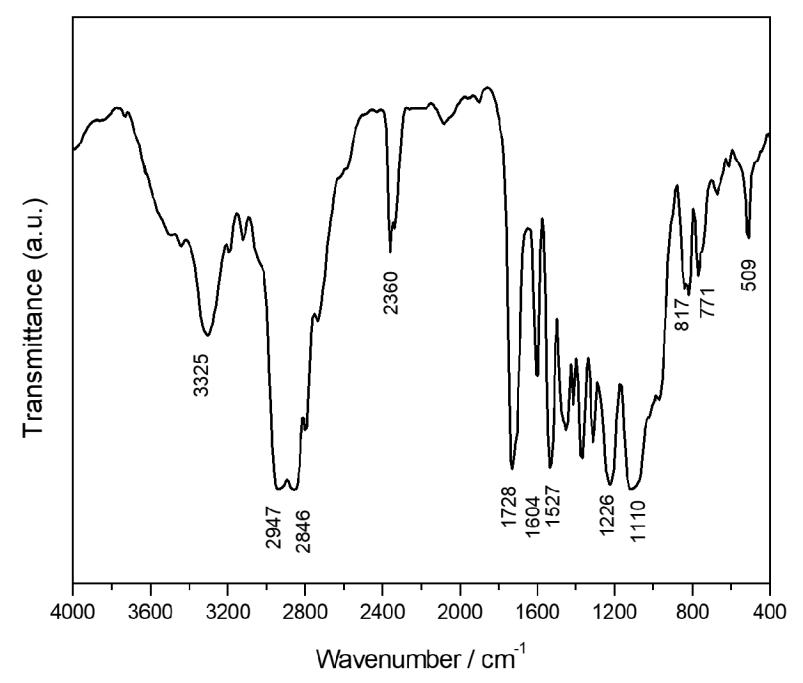

Figure 4: FTIR curve of TPU

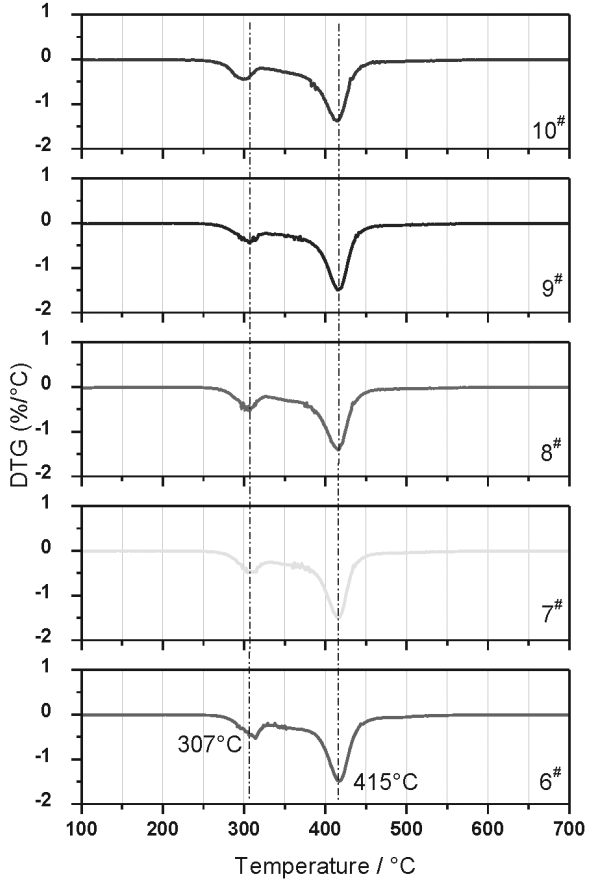

hydroxyl, isocyanate, ureido, amide, biuret and allophanate. Figure 4 shows the infrared spectrum of the TPU. The imino group has its absorption peak at $3250-3500 \mathrm{~cm}^{-1}$ and the hydroxyl group also has its absorption peak in the region of $3400-3500 \mathrm{~cm}^{-1}$. However, the peak is rarely found for the hydroxyl group of polyurethane. The peak at $3325 \mathrm{~cm}^{-1}$ is mainly imino $(\mathrm{N}-\mathrm{H})$ and another absorption peak of the imino group is found at $1527 \mathrm{~cm}^{-1}$. The absorption peak at $2360 \mathrm{~cm}^{-1}$ indicates that the TPU contains isocyanate groups (-NCO), showing that the prepolymer is not completely extended during the synthesis of the TPU. The broad absorption peak near $2900 \mathrm{~cm}^{-1}$ indicates the vibration of the hydrocarbon group $\left(-\mathrm{CH}_{2}\right.$ and $\left.-\mathrm{CH}_{3}\right)$ and at $1300-1500 \mathrm{~cm}^{-1}$, there is also the absorption peak of the hydrocarbon group. The absorption peaks at $1728 \mathrm{~cm}^{-1}$ and $1604 \mathrm{~cm}^{-1}$ are mainly due to the carbonyl $(\mathrm{C}=\mathrm{O})$ vibrations in the urethane group, ureido group or amide group, and they are characteristic of synthetic polyurethane. At $1226 \mathrm{~cm}^{-1}$, there is the absorption peak of the $\mathrm{C}-\mathrm{O}$ group from the ester group and the $\mathrm{C}-\mathrm{O}$ group of the hydroxyl group, connected with carbochain. At $1110 \mathrm{~cm}^{-1}$, there is the absorption peak of the ether group (-O-) from the urethane group. The multiple absorption peaks in the range of $500-900 \mathrm{~cm}^{-1}$ indicate the vibrations of the benzene ring from isocyanate.

\section{CONCLUSIONS}

Based on the design of a polyurethane hard segment and isocyanate index, 10 kinds of TPU were synthesized using the prepolymer method. With the effect of purity of the raw materials and the environmental humidity in 
the synthesis process of TPU, the molecular weight of TPU deviates from the theoretical value of the isocyanate index, and the side reaction of the NCO group makes TPU branched and crosslinked so that the molecular weight of some samples cannot be measured. The TPU hard-segment content is different; the hard-segment and soft-segment phases are different, resulting in the soft and hard segments interacting with each other; the heat absorption is also found to be different with DSC. From the perspective of the TPU molecular weight, the heat resistance of the TPU with $20 \%$ hard-segment content is better than that of $40 \%$ hard segment of TPU.

\section{Acknowledgment}

The authors acknowledge the financial supports provided by the National Natural Science Foundation of China (Grant No. 51902294), Applied Basic Research Project of Shanxi Province (Grant No. 201901D211206), Project in Scientific Innovation of Colleges and Universities of the Shanxi Province of China (Grant No. 201802073) and the Opening Foundation of the Shanxi Key Laboratory of Advanced Manufacturing Technology (Grant No. XJZZ201808).

\section{REFERENCES}

${ }^{1}$ A. Atiqah, M. T. Mastura, B. A. Ahmed Ali, M. Jawaid, S. M Sapuan, A review on polyurethane and its polymer composites, Curr. Org. Synth., 14 (2017), 233-248, doi:10.2174/ 1570179413666160831124749

${ }^{2}$ H. Hengameh, Waterborne polyurethanes: a review, J. Disper. Sci. Technol., 3 (2017), 507-516, doi:10.1080/01932691.2017.1327818

${ }^{3}$ J. O. Akindoyo, M. D. H. Beg, S. Ghazali, M. R. Islam, N. Jeyaratnam, A. R. Yuvarajc, Polyurethane types, synthesis and applications - a review, RSC Adv., 115 (2016), 114453-114482, doi:10.1039/ c6ra14525f

${ }^{4}$ X. B. Wang, Q. M. Jin, J. Y. Zhang, Y. Li, S. S. Li, H. Mikulčić, M. Vujanović, H. Z. Tan, N. Duić, Soot formation during polyurethane (PU) plastic pyrolysis: The effects of temperature and volatile residence time, Energ. Convers. Manage., 164 (2018), 353-362, doi:10.1016/j.enconman.2018.02.082

${ }^{5}$ A. D. Easley, M. B. B. Monroe, S. M. Hasan, A. C. Weems, J. Frederick, D. J. Maitland, Shape memory polyurethane-urea foams with improved toughness, J. Appl. Polym. Sci., 136 (2019), 47268, doi:10.1002/app.47268

${ }^{6}$ D. W. Lee, H. N. Kim, D. S. Lee, Design of azomethine diols for efficient self-healing of strong polyurethane elastomers, Molecules, 23 (2018), 2928, doi:10.3390/molecules 23112928

${ }^{7}$ E. Zdraveva, B. Mijovic, E. G. Bajsic, V. Grozdanic, The efficacy of electrospun polyurethane fibers with $\mathrm{TiO} 2$ in a real time weathering condition, Text. Res. J., 88 (2018), 2445-2453, doi:10.1177/ 0040517517723025

${ }^{8}$ Z. M. Jia, G. Q. Yuan, X. P. Feng, Y. Zou, Numerical study on the mechanical behavior of a polyurethane adhesive under high strain rate, Compos. Part B: Eng., 158 (2019), 131-140, doi:10.1016/ j.compositesb.2018.08.110

${ }^{9}$ J. Joseph, R. M. Patel, A. Wenham, J. R. Smith, Biomedical applications of polyurethane materials and coatings, T. I. Met. Finish., 96 (2018), 121-129, doi:10.1080/00202967.2018.1450209
${ }^{10}$ V. Yakushin, A. Abolins, D. Vilsone, I. Sevastyanova, Polyurethane coatings based on linseed oil phosphate ester polyols with intumescent flame retardants, Fire Mater., 43 (2019), 92-100, doi:10.1002/fam.2672

${ }^{11}$ D. C. Huang, Y. Zhou, Y. Xiang, M. J. Shu, H. X. Chen, B. Yang, X. H. Liao, Polyurethane/doxorubicin nanoparticles based on electrostatic interactions as $\mathrm{pH}$-sensitive drug delivery carriers, Polym. Int., 67 (2018), 1186-1193, doi:10.1002/pi.5618

${ }^{12}$ D. Pezo, M. Fedeli, O. Bosetti, C. Nerin, Aromatic amines from polyurethane adhesives in food packaging: The challenge of identification and pattern recognition using Quadrupole-Time of Flight-Mass Spectrometry(E), Anal. Chim. Acta., 756 (2012), 49-59, doi:10.1016/j.aca.2012.10.031

${ }^{13}$ D. Turan, G. Gunes, F. S. Güner, Synthesis, characterization and $\mathrm{O}_{2}$ permeability of shape memory polyurethane films for fresh produce packaging, Packag. Technol. Sci., 29 (2016), 415-427, doi:10.1002/pts.2222

${ }^{14}$ A. Antunes, A. Henriques, F. Lima, J. Ferra, J. Martins, L. Carvalho, F. D. Magalhaes, Postformable and self-healing finish foil based on polyurethane-impregnated paper, Ind. Eng. Che. M. Res., 55 (2016), 12376-12386, doi:10.1021/acs.iecr.6b02477

${ }^{15}$ S. K. Dogan, S. Boyacioglu, M. Kodal, O. Gokce, G. Ozkoc, Thermally induced shape memory behavior, enzymatic degradation and biocompatibility of PLA/TPU blends: "Effects of compatibilization", J. Mech. Behav. Biomed., 71 (2017), 349-361, doi:10.1016/j.jmbbm. 2017.04.001

${ }^{16}$ P. Alagi, Y. J. Choi, J. Seog, S. C. Hong, Efficient and quantitative chemical transformation of vegetable oils to polyols through a thiol-ene reaction for thermoplastic polyurethanes, Ind. Crop. Prod., 87 (2016), 78-88, doi:10.1016/j.indcrop.2016.04.027

${ }^{17}$ W. Q. Lei, C. Q. Fang, X. Zhou, Y. L. Cheng, R. Yang, D. H. Liu, Morphology and thermal properties of polyurethane elastomer based on representative structural chain extenders, Thermochim. Acta, 653 (2017), 116-125, doi:10.1016/j.tca.2017.04.008

${ }^{18}$ Y. Xiao, L. Jiang, Z. M. Liu, Y. Yuan, P. Y. Yan, C. L. Zhou, J. X. Lei, Effect of phase separation on the crystallization of soft segments of green waterborne polyurethanes, Polym. Test., 60 (2017), 160-165, doi:10.1016/j.polymertesting.2017.03.029

${ }^{19}$ R. E. Yu, X. J. Zhu, X. Zhou, Y. F. Kou, M. R. Zhang, C. Q. Fang, Rheological properties and storage stability of asphalt modified with nanoscale polyurethane emulsion, Petrol. Sci. Technol., 36 (2018), 85-90, doi:10.1080/10916466.2017.1405028

${ }^{20}$ R. E. Yu, X. J. Zhu, M. R. Zhang, C. Q. Fang, Investigation on the short-term aging-resistance of thermoplastic polyurethane-modified asphalt binders, Polymers, 10 (2018), 1189, doi:10.3390/ polym 10111189

${ }^{21}$ R. E. Yu, X. J. Zhu, J. B. Hu, W. Zhao, C. Q. Fang, Preparation of graphene oxide and its modification effect on base asphalt, Fuller., Nanotub. Car. N., 27 (2019), 256-264, doi:10.1080/1536383X.2019. 1566224

${ }^{22}$ R. E. Yu, X. L. Liu, M. R. Zhang, X. J. Zhu, C. Q. Fang, Dynamic stability of ethylene-vinyl acetate copolymer crumb rubber modified asphalt, Constr. Build. Mater., 156 (2017), 284-292, doi:10.1016/ j.conbuildmat.2017.08.182

${ }^{23}$ D. Kim, D. G. Lee, J. C. Kim, C. S. Lim, N. S. Kong, J. H. Kim, H. W. Jung, S. M. Noh, Y. Park, Effect of molecular weight of polyurethane toughening agent on adhesive strength and rheological characteristics of automotive structural adhesives, Int. J. Adhes. Adhes., 74 (2017), 21-27, doi:10.1016/j.ijadhadh.2016.12.006

${ }^{24}$ B. Lucio, J. L. Fuente, Non-isothermal DSC and rheological curing of ferrocene-functionalized, hydroxyl-terminated polybutadiene polyurethane, React. Funct. Polym., 107 (2016), 60-68, doi:10.1016/ j.reactfunctpolym.2016.08.002 